\title{
Systemic neutrophil-to-lymphocyte ratio in colorectal cancer: the relationship to patient survival, tumour biology and local lymphocytic response to tumour
}

\author{
J K Pine ${ }^{1,2}$, E Morris ${ }^{3}$, G G Hutchins ${ }^{2}$, N P West ${ }^{2}$, D G Jayne ${ }^{4}$, P Quirke ${ }^{2}$ and K R Prasad ${ }^{\star 1}$ \\ ${ }^{1}$ Department of HPB Surgery, St James's University Hospital, Beckett Street, Leeds LS9 7TF, UK; ${ }^{2}$ Department of Pathology and \\ Tumour Biology, Leeds Institute of Cancer and Pathology, University of Leeds LS9 7TF, Leeds, UK; ${ }^{3}$ Cancer Epidemiology Group, \\ Leeds Institute of Cancer and Pathology, St James's University Hospital, Beckett Street, Leeds LS9 7TF, UK and ${ }^{4}$ Department of \\ Colorectal Surgery, Leeds Institute of Biomedical \& Clinical Sciences, St James's University Hospital, Beckett Street, Leeds LS9 \\ 7TF, UK
}

Background: Colorectal cancer (CRC) is a major cause of mortality and morbidity. The impact of inflammatory biomarkers (C-reactive protein etc.) on CRC is increasingly studied including systemic neutrophil-to-lymphocyte ratio (NLR) as they seem to predict outcome.

Methods: All patients who underwent curative resection for CRC from 2000 to 2004 at Leeds Teaching Hospitals NHS Trust had pre-operative NLR calculated. Demographic, histopathological and survival data were collected. Tissue microarrays were created and stained to determine the mismatch repair (MMR) protein status of each tumour. Local lymphocytic response to the tumour was assessed and graded.

Results: About 358 patients were eligible. Of these 88 had an NLR $\geqslant 5$, which predicted lower overall survival and greater disease recurrence. A high NLR is associated with higher pT- and pN-stage and a greater incidence of extramural venous invasion. MMR protein status was not associated with NLR. A pronounced lymphocytic reaction at the invasive margin (IM) indicated a better prognosis and was associated with a lower NLR.

Conclusion: Neutrophil-to-lymphocyte ratio predicts disease-free and overall survival and is associated with a more aggressive tumour phenotype. The lymphocytic response to tumour at the IM is associated with NLR however dMMR is not. Neutrophil-tolymphocyte ratio is a cheap, easy-to-access test that predicts outcome in CRC.

Colorectal cancer (CRC) is the second most common cause of cancer death in Western Europe and North America. In the UK in 2010, there were 40695 newly diagnosed CRCs and 15708 CRCrelated deaths (CRUK, 2010). Advances in surgical technique, screening and adjuvant oncological therapies have improved outcomes but it remains a significant cause of mortality (Martling et al, 2000; Gill et al, 2004). Adjuvant therapies, while improving survival in certain groups of patients, cause significant morbidity and it is therefore vital to identify prognostic factors that indicate which patients would benefit from this type of treatment. Traditionally, prognosis in CRC is predicted by histopathological parameters, including staging criteria such as Dukes' or TNM staging (Wood, 1971; Deans et al, 1994). Other factors such as circumferential resection margin involvement, depth of extramural 
invasion and extramural venous invasion (EMVI) are also important (Courtney et al, 2009). More recently, increasing attention has been paid to genetic and epigenetic factors and their influence on outcome. The presence of microsatellite instability has been shown to be associated with better prognosis (Gryfe et al, 2000; Hutchins et al, 2011). The identification of specific mutations can determine prognosis (Hutchins et al, 2011) and response to treatment, such as RAS mutations predicting a poor response to cetuximab therapy (Lievre et al, 2006).

The role of the immune system in cancer pathogenesis has been given an increasingly prominent role. There is a link between inflammation and outcome in a number of solid tumours (Nozoe et al, 2001; McKeown et al, 2004; Hilmy et al, 2005; Jamieson et al, 2005; Gerhardt et al, 2006; Lamb et al, 2008). The relationship between the various inflammatory factors in the tumour microenvironment and tumour growth, invasion and metastasis has been explored (Balkwill and Mantovani, 2001; Coussens and Werb, 2002; de Visser et al, 2006; Hanahan and Weinberg, 2011). Cancer cells generate an immune response in the host. The strength and type of this response may have an impact on disease progression.

A number of studies have examined the systemic inflammatory response to tumour and its impact on prognosis. Elevated C-reactive protein (CRP), produced as part of the acute-phase response, has been associated with poor outcome in multiple solid tumours including CRC (McMillan et al, 2003; Wong et al, 2007). During an acute inflammatory response the ratio of different leucocyte subsets is altered. There is a neutrophilia often accompanied by a relative lymphocytopenia (Zahorec, 2001). Therefore a simple measure of systemic inflammation can be generated by calculating the neutrophil-to-lymphocyte ratio (NLR). In 2005 an association was demonstrated between NLR and outcome in CRC but this was not significant on multivariate analysis (Walsh et al, 2005). This marker has already been demonstrated to be an independent prognostic factor following resection of CRC liver metastases (Halazun et al, 2008). Since then multiple studies have indicated that NLR predicts outcome in a variety of stages in CRC and following chemotherapy (Ding et al, 2010; Chua et al, 2011; Hung et al, 2011; Chiang et al, 2012; Kaneko et al, 2012; Mallappa et al, 2013; Absenger et al, 2013; Malietzis et al, 2014). However, none have attempted to examine the underlying mechanisms.

A morphological sub-type of CRC associated with mismatch repair (MMR) protein deficiency, as a consequence of microsatellite instability, has been noted to provoke a strong host response to tumour in the form of a pronounced lymphocytic infiltrate (Dolcetti et al, 1999; Guidoboni et al, 2001; Drescher et al, 2009). These cancers also seem to have a better prognosis compared with other types of CRC (Popat et al, 2005). The presence of tumourinfiltrating lymphocytes in CRC has also been shown to confer a better prognosis (Pages et al, 2005; Galon et al, 2006).

The aim of this study was to examine the relationship between pre-operative NLR and clinico-pathological features in a cohort of CRC patients undergoing curative resection and outcome. We also determined the MMR status and local lymphocytic response to tumour and its association with NLR.

\section{MATERIALS AND METHODS}

Patients who underwent potentially curative resection for CRC at Leeds Teaching Hospitals NHS Trust between September 2000 and January 2004 were identified. All patients included in the study had a full blood count (including a white cell differential count) performed a maximum of 7 days prior to their surgery. Exclusion criteria included any evidence of colonic perforation or documented sepsis. Sepsis was defined as a temperature $>38{ }^{\circ} \mathrm{C}$ in combination with a positive microbiological culture sample within $48 \mathrm{~h}$.

Ethical approval for this project was granted by Leeds (East) Ethics Committee (reference number: 08/H1306/86).

Data collection. All participants had histopathologically proven colorectal adenocarcinoma. A variety of data was collected from the histopathology reports including TNM/Dukes' staging, evidence of EMVI and of resection margin status.

The white cell count and differential was obtained via the Siemens Advia 2120 (Siemens, Erlangen, Germany) flow cytometer. Overall neutrophil count was measured in $10^{9} 1^{-1}$ (normal range $\left.2.0-7.5 \times 10^{9} 1^{-1}\right)$. Overall lymphocyte count was measured in $10^{9} 1^{-1}$ (normal range $1.0-4.5 \times 10^{9} 1^{-1}$ ). Neutrophil-to-lymphocyte ratio was calculated and a predefined value of $\geqslant 5$ was taken to represent an elevated NLR (Walsh et al, 2005).

Survival data. Data regarding patient survival were collected from the Northern and Yorkshire Cancer Registry and Information Service (NYCRIS). This was used to calculate the overall patient survival. Overall survival was defined as the time from date of first surgery to date of death from any cause. Censor points were last attendance at hospital or date of death. Data regarding disease recurrence were collected from radiological, histopathological and endoscopic records, and disease-free survival was calculated. Disease-free survival was defined as date of first surgery to date on which disease recurrence, either local or distant, was first detected. Follow-up protocol was standardized within the colorectal department at Leeds Teaching Hospitals NHS Trust.

Determination of MMR status. Tissue microarrays (TMAs) were constructed using three individual $0.6 \mathrm{~mm}$ cores of formalin-fixed paraffin-embedded tumour tissue for each patient. Sections were taken from the TMAs and stained for the MMR proteins, hMLH-1 and hMSH-2, using pre-determined immunohistochemical protocols. The glass slides were scanned using an Aperio XT slide scanner (Aperio Technologies Inc, San Diego, CA, USA) and visualised using Aperio ImageScope (Aperio Technologies Inc). Each individual tumour core was scored as positive or negative, with negative defined as the absence of any staining within tumour cells. Staining within immune cells was used as an internal positive control. Cases scored as negative for either marker were taken to be MMR-deficient cancers. In cores with no tumour tissue, assessment of MMR status was not possible and these were classed as unknown.

Assessment of peritumoral lymphocytes. Slides were cut from each of the whole tissue blocks and stained with haematoxylin and eosin. These were scanned and viewed digitally so that the lymphocytic response to tumour could be assessed.

The scoring system was based on the study by Klintrup et al (2005). This assessed the tumour centre and invasive margin (IM). Invasive margin was defined as the interface between the normal host tissue and the invading edge of the tumour. At the margin the deepest point of invasion was chosen. Each area was scored as 1 to 3 where 1 was none or low density (no reaction or a mild patchy lymphocytic response), 2 moderate density (band-like infiltrate with some cancer cell destruction) and 3 high density (prominent inflammatory reaction with a cup-like zone and destruction of cancer cells). All slides were scored by the author based on the described parameters. To confirm the consistency of scoring, a total of 120 tumour specimens from the CRC group were scored by two independent histopathologists, who were blinded to outcome (NPW and GGH).

Statistical analysis. Data are presented as mean or median (range). Comparisons between the means of normally distributed groups were performed using Student's $t$-test. Non-parametric data was analysed using the $\chi^{2}$-test. 
Univariate survival trends were compared using Kaplan-Meier curves and significant differences determined via the log rank test. To determine whether variables were independently linked to prognosis, the Cox proportional hazard model was used. Significant factors on univariate analysis were entered into a multivariate model. A $P$-value $<0.05$ was considered significant. All statistical analysis was performed using SPSS version 16 (SPPS Inc., Chicago, IL, USA).

\section{RESULTS}

From the cohort, 400 patients with pre-operative bloods taken within 1 week prior to surgery were identified. About 42 patients were excluded due to the presence of bowel perforation or sepsis preoperatively, leaving 358 patients in the study group. All patients have follow-up of $>4$ years therefore patients were censored at 4 years for the survival analysis.

Demographics. The study population comprised of 202 (56.4\%) males and $156(43.6 \%)$ females. The median age was 74 years (range 32-95). About 261 cases were cancers of the colon and 97 were rectal. Of the colonic cancers, 141 were right sided and 120 were left sided.

Clinico-pathological data. Clinico-pathological data is presented in Supplementary Table 1. About $38(10.6 \%)$ patients were staged as Dukes' A, 163 (45.5\%) as Dukes' B, 119 (33.4\%) were Dukes' C and $37(10.5 \%)$ were stage D. About 138 (38.5\%) demonstrated evidence of EMVI. About 310 (86.6\%) patients had complete R0 resections, while in $37(10.3 \%)$ the resection margin was involved microscopically (R1). R1 was defined as a margin $\leqslant 1 \mathrm{~mm}$ clear of tumour.

Neutrophil-to-lymphocyte ratio. Neutrophil-to-lymphocyte ratio was calculated for each patient producing two groups: high NLR $(\mathrm{NLR} \geqslant 5)$ and low NLR $(\mathrm{NLR}<5)$. This cut-off was used as previously cited in the relevant literature (Walsh et al, 2005). The median age for both groups was 74 years. The distribution of gender in each group is similar (Table 1). The site of tumour in the low NLR group was $81.2 \%$ colon and $18.8 \%$ rectum compared with $89.4 \%$ colon and $10.6 \%$ rectum in the high NLR group $(P=0.186)$.

Table 1 contains data comparing clinico-pathological factors within the high and low NLR groups. Median maximum tumour diameter in the NLR $<5$ group was $4.0 \mathrm{~cm}$ compared with $3.5 \mathrm{~cm}$ in the NLR $\geqslant 5$ group $(P=0.153)$. The grade of differentiation in each group was similar. It is clear from Table 1 that NLR is associated with a more advanced, aggressive tumour type. The NLR $\geqslant 5$ group tumours are more likely to have a higher pT-stage $(P<0.001)$ and $\mathrm{pN}$-stage $(P=0.014)$. They are more likely to be associated with more positive lymph nodes and evidence of EMVI. The percentage of the NLR $\geqslant 5$ group that was stage D/IV was $20.5 \%$ compared with $8.6 \%$ in the low NLR group.

Patient survival. Overall survival for the entire cohort is demonstrated (separated by Dukes' stage) in Supplementary Figure 1. The difference between the four groups is significant $(P<0.001)$. When the overall survival for the high NLR group is compared with the low NLR group the outcomes for those with an NLR $\geqslant 5$ is significantly poorer (Figure $1 \mathrm{~A}$ ). Thirty-day mortality (3.7 vs $19.3 \%, P<0.001$ ), 90-day mortality (7.4 vs $24.0 \%, P<0.001$ ) and 4-year survival (59.6 vs $27.3 \%, P<0.001)$ are significantly worse in the high NLR group. Disease-free survival also demonstrated poorer survival in the NLR $\geqslant 5$ group (Figure $1 \mathrm{~B}$ ). Overall survival in the NLR $<5$ and $\geqslant 5$ groups by Dukes' stage is shown in Supplementary Figure 2. This indicates that the prognostic effect of NLR may be independent of Dukes' stage.
Univariate/multivariate analysis. Univariate analysis for overall survival was performed on age, gender, NLR and clinicopathological factors. The results can be seen in Table 1 with significant factors including age, NLR, CRP level, number of positive lymph nodes, EMVI, pT- and pN-stage, and Dukes' stage. The hazard ratio (HR) for NLR was 2.62 (95\% CI 1.93-3.55, $P<0.001)$ making it one of the stronger predictors on univariate analysis. Significant factors $(P<0.05)$ were put through a multivariate model and the results are shown in Table 1 . The factors that remained significant were age, NLR and Dukes' stage C and stage D.

A similar analysis was performed for disease-free survival. On univariate analysis, NLR, number of positive lymph nodes, EMVI, complete resection and Dukes' stage were significant. On multivariate analysis, NLR, EMVI and Dukes stage C remained significant (Supplementary Table 2).

\section{MMR status and NLR}

Demographics. The incidence of MMR deficiency compared with NLR of CRC patients is shown in Table 2. Demographic data shown in Supplementary Table 3 demonstrates some of the features associated with MMR-deficient tumours, namely female gender and right-sided tumours.

Association between MMR status and NLR. The ratios of NLR $<5$ and $\geqslant 5$ against the presence, or otherwise, of the MMR proteins are shown in Table 2. There appears to be no association between the two groups.

Tumour-associated lymphocytes in CRC. The intraclass correlation co-efficient (ICCC) between the author and the observers was $0.70(\mathrm{GGH})$ and $0.87(\mathrm{NPW})$ at the IM and $0.88(\mathrm{GGH})$ and 0.85 $(\mathrm{NPW})$ at the tumour centre. Inter-observer ICCCs $>0.7$ are considered acceptable (Streiner and Norman, 1995).

Based on the original grading system (Klintrup et al, 2005), Kaplan-Meier curves for overall survival were constructed using the results obtained from the IM (Figure 2A). These demonstrated a significant difference in patient outcomes for each group with a more pronounced lymphocytic reaction being associated with a better prognosis $(P=0.004)$. The same curves were produced for the lymphocytic reaction seen at the tumour centre but no significant difference was observed between the groups (Figure 3).

Characteristics of the mild $v$ s pronounced lymphocytic reaction (at the IM) groups. These characteristics are shown in Table 3. There was no difference in age or gender between the two groups. There is a trend towards colonic tumours being more likely to produce a moderate-to-severe lymphocytic reaction than rectal tumours but this did not reach statistical significance. A moderateto-severe lymphocytic reaction at the IM is associated with MMR deficiency $(P=0.040)$, decreased incidence of EMVI $(P=0.010)$ and lower Dukes' stage $(P=0.001)$. There is a significant association between raised NLR and a milder degree of lymphocytic infiltration at the IM with $15.3 \%$ of the moderate and severe lymphocytic response groups having an NLR $\geqslant 5$ compared with $29.2 \%$ of the mild lymphocytic response group $(P=0.005)$.

On univariate analysis, grade of lymphocytic reaction at the IM was a significant prognostic factor (HR 1.75, 95\% CI 1.24-2.47, $P=0.001)$. However, when it is included in the multivariate model for overall survival in this group it is not significant (Table 4).

Disease-free survival by grade of lymphocytic reaction at the $I M$. Disease-free survival for the two lymphocytic response groups (none/mild $v s$ moderate/severe) was calculated. The survival curves (Figure $2 \mathrm{~B}$ ) show a clear difference between groups $(P=0.010)$. On univariate analysis, grade of lymphocytic reaction at the IM was a 
Table 1. Univariate and multivariate analysis for overall survival (covariates included in multivariate model highlighted in bold)

\begin{tabular}{|c|c|c|c|c|c|c|c|}
\hline \multirow[b]{2}{*}{ Covariate } & \multirow[b]{2}{*}{$N$} & \multicolumn{3}{|c|}{ Univariate } & \multicolumn{3}{|c|}{ Multivariate } \\
\hline & & $P$-value & HR & $95 \% \mathrm{Cl}$ & $P$-value & HR & $95 \% \mathrm{Cl}$ \\
\hline \multicolumn{8}{|l|}{ NLR } \\
\hline $\begin{array}{l}<5 \\
\geqslant 5\end{array}$ & $\begin{array}{c}270 \\
88\end{array}$ & $-\overline{0.001}$ & $\begin{array}{c}1.00 \\
2.616\end{array}$ & $\frac{-}{1.925-3.553}$ & $-\overline{0.001}$ & $\begin{array}{c}1.00 \\
1.819\end{array}$ & $\frac{-}{1.310-2.526}$ \\
\hline \multicolumn{8}{|c|}{ Age (years) } \\
\hline $\begin{array}{l}\leqslant 70 \\
>70\end{array}$ & $\begin{array}{l}129 \\
229\end{array}$ & $<\overline{0.001}$ & $\begin{array}{c}1.00 \\
2.549\end{array}$ & $\frac{-}{1.799-3.612}$ & $<\overline{0.001}$ & $\begin{array}{c}1.00 \\
2.964\end{array}$ & $\begin{array}{c}- \\
2.045-4.297\end{array}$ \\
\hline \multicolumn{8}{|l|}{ Gender } \\
\hline $\begin{array}{l}M \\
F\end{array}$ & $\begin{array}{l}202 \\
156\end{array}$ & $\overline{0.920}$ & $\begin{array}{c}1.00 \\
1.015\end{array}$ & $\begin{array}{c}- \\
0.758-1.360\end{array}$ & - & - & - \\
\hline \multicolumn{8}{|l|}{ CRP (U) } \\
\hline $\begin{array}{l}\leqslant 10 \\
>10\end{array}$ & $\begin{array}{l}74 \\
90\end{array}$ & $0 . \overline{025}$ & $\begin{array}{c}1.00 \\
1.640\end{array}$ & $\frac{-}{1.063-2.528}$ & - & - & $\begin{array}{l}- \\
-\end{array}$ \\
\hline \multicolumn{8}{|c|}{ Total lymph nodes found } \\
\hline $\begin{array}{l}0-15 \\
>15\end{array}$ & $\begin{array}{l}178 \\
178\end{array}$ & $\overline{0.020}$ & $\begin{array}{c}1.00 \\
1.419\end{array}$ & $\frac{-}{1.057-1.904}$ & - & $\begin{array}{l}- \\
-\end{array}$ & - \\
\hline \multicolumn{8}{|l|}{ EMVI } \\
\hline $\begin{array}{l}\mathrm{Y} \\
\mathrm{N}\end{array}$ & $\begin{array}{l}138 \\
213\end{array}$ & $<\overline{0.001}$ & $\begin{array}{c}1.00 \\
2.210\end{array}$ & $\frac{-}{1.641-2.976}$ & $\overline{0.139}$ & $\begin{array}{c}1.00 \\
1.294\end{array}$ & $\begin{array}{c}- \\
0.920-1.820\end{array}$ \\
\hline \multicolumn{8}{|l|}{ pT-stage } \\
\hline $\begin{array}{l}1 \\
2 \\
3 \\
4\end{array}$ & $\begin{array}{c}11 \\
32 \\
212 \\
98\end{array}$ & $\begin{array}{l}-\overline{-} \\
0.596 \\
0.757 \\
0.036\end{array}$ & $\begin{array}{l}1.00 \\
0.731 \\
1.171 \\
2.931\end{array}$ & $\begin{array}{c}- \\
0.229-2.330 \\
0.430-3.188 \\
1.070-8.024\end{array}$ & $\begin{array}{l}- \\
- \\
-\end{array}$ & $\begin{array}{l}- \\
- \\
-\end{array}$ & $\begin{array}{l}- \\
- \\
-\end{array}$ \\
\hline \multicolumn{8}{|l|}{ pN-stage } \\
\hline $\begin{array}{l}0 \\
1 \\
2\end{array}$ & $\begin{array}{l}203 \\
88 \\
65\end{array}$ & $\begin{array}{c}-\overline{-} \\
0.048 \\
<0.001\end{array}$ & $\begin{array}{c}1.00 \\
1.454 \\
3.712\end{array}$ & $\begin{array}{c}- \\
1.002-2.108 \\
2.615-5.272\end{array}$ & $\begin{array}{l}- \\
- \\
-\end{array}$ & $\begin{array}{l}- \\
- \\
-\end{array}$ & $\begin{array}{l}- \\
- \\
-\end{array}$ \\
\hline \multicolumn{8}{|c|}{ Complete resection } \\
\hline $\begin{array}{l}\mathrm{Y} \\
\mathrm{N}\end{array}$ & $\begin{array}{c}310 \\
37\end{array}$ & $\overline{0.130}$ & $\begin{array}{c}1.00 \\
1.435\end{array}$ & $\frac{-}{0.917-2.246}$ & $\begin{array}{l}- \\
-\end{array}$ & - & - \\
\hline \multicolumn{8}{|c|}{ Site of tumour } \\
\hline $\begin{array}{l}\text { Colon } \\
\text { Rectum }\end{array}$ & $\begin{array}{c}261 \\
97\end{array}$ & $0 . \overline{161}$ & $\begin{array}{c}1.00 \\
0.783\end{array}$ & $\frac{-}{0.556-1.102}$ & - & $\begin{array}{l}- \\
-\end{array}$ & $\begin{array}{l}- \\
-\end{array}$ \\
\hline \multicolumn{8}{|c|}{ Dukes' stage } \\
\hline $\begin{array}{l}\text { A } \\
\text { B } \\
\text { C } \\
\text { D }\end{array}$ & $\begin{array}{c}38 \\
163 \\
119 \\
37\end{array}$ & $\begin{array}{c}-\overline{-} \\
0.510 \\
0.02 \\
<0.001\end{array}$ & $\begin{array}{c}1.00 \\
1.223 \\
2.701 \\
6.776\end{array}$ & $\begin{array}{c}- \\
0.672-2.228 \\
1.430-5.100 \\
3.408-13.474\end{array}$ & $\begin{array}{c}-\overline{-} \\
0.999 \\
0.025 \\
<0.001\end{array}$ & $\begin{array}{l}1.00 \\
0.999 \\
2.097 \\
6.665\end{array}$ & $\begin{array}{c}- \\
5.33-1.875 \\
1.098-4.007 \\
3.241-13.707\end{array}$ \\
\hline
\end{tabular}

significant prognostic factor (HR 1.87, 95\% CI 1.07-3.30, $P=0.029$ ). On multivariate analysis this was not significant (Table 5).

\section{DISCUSSION}

This study assessed the impact of NLR on a retrospective series of CRC patients. The cohort consisted of a variety of patients presenting at Dukes' stage A to C (with a small proportion of patients with stage IV disease and resectable liver metastases). Histopathological parameters such as the number of positive lymph nodes and evidence of EMVI were shown to be prognostic. As expected various staging methods (TNM, Dukes') also predict outcome. These data demonstrated that pre-operative NLR predicted survival. By splitting the cohort into two groups (NLR $<5$ and NLR $\geqslant 5$ ) the difference in outcome was illustrated by survival curves for overall and disease-free survival (Figure 1A and B). On univariate analysis of overall survival, NLR was shown to be prognostic (HR 2.62, 95\% CI 1.93-3.55, $P=<0.001$ ). Neutrophil- to-lymphocyte ratio, along with age and Dukes' stage, remains significant in a multivariate model. When the high and low NLR groups are analysed it becomes apparent that NLR is associated with more advanced, aggressive tumour biology with more lymph node metastases and EMVI.

To further assess the effect of tumour biology on NLR, we investigated the role of MMR status. Our MMR-deficient cancers had typical characteristics of this tumour type: female gender and right-sided lesions (Lanza et al, 2006). Unlike many series MMR status did not demonstrate any differences in survival. Mismatch repair-deficient cancers were associated with a more prominent peritumoral lymphocytosis. It is thought that the anti-tumoural effect of T-lymphocytes within the infiltrative population may account for the better outcomes observed in this group. As a component of NLR is circulating lymphocytes, we postulated that the lymphocytic reaction seen in MMR cancers may be associated with NLR. However, on analysis no correlation between MMR status and NLR was observed. This may be a type II error and larger series/meta-analyses would be required to confirm or refute this hypothesis. 


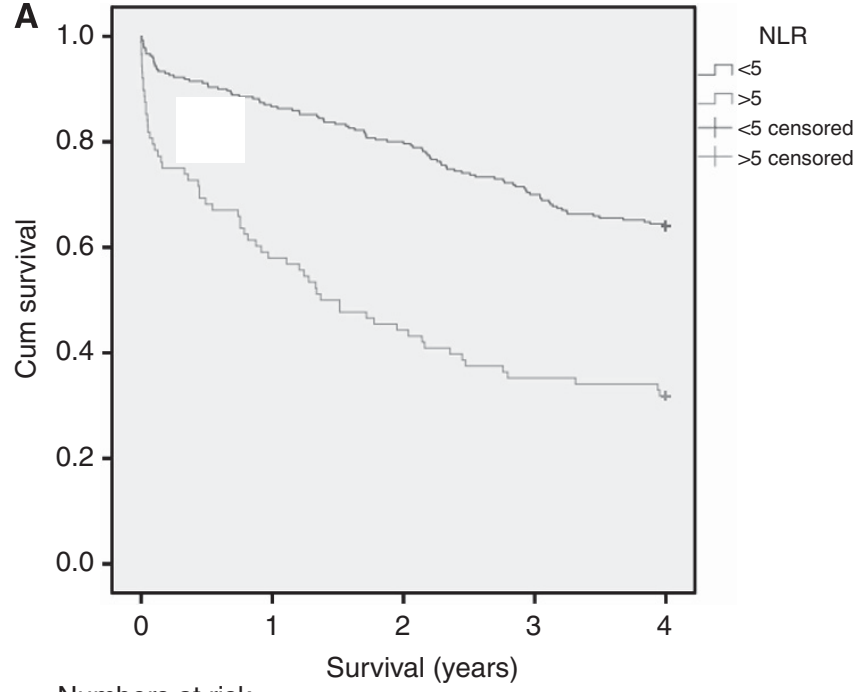

Numbers at risk

\begin{tabular}{|l|c|c|c|c|c|}
\hline Years & $\mathbf{0}$ & $\mathbf{1}$ & $\mathbf{2}$ & $\mathbf{3}$ & $\mathbf{4}$ \\
\hline $\mathrm{NLR}<5$ & 270 & 234 & 216 & 189 & 174 \\
\hline $\mathrm{NLR} \geqslant 5$ & 88 & 51 & 39 & 31 & 28 \\
\hline
\end{tabular}

B



Numbers at risk

\begin{tabular}{|l|c|c|c|c|c|}
\hline Years & $\mathbf{0}$ & $\mathbf{1}$ & $\mathbf{2}$ & $\mathbf{3}$ & $\mathbf{4}$ \\
\hline NLR $<5$ & 247 & 211 & 191 & 171 & 157 \\
\hline NLR $\geqslant 5$ & 70 & 37 & 32 & 27 & 25 \\
\hline
\end{tabular}

Figure 1. Kaplan-Meier curves comparing survival for NLR $<5$ vs $N L R \geqslant 5$. (A) Overall survival $(n=358, P<0.001, H R 2.616,95 \% \mathrm{Cl}$ 1.925-3.553). (B) Disease-free survival $(n=317, P<0.001, \mathrm{HR} 2.547$, $95 \% \mathrm{Cl} 1.521-4.265)$. NLR= neutrophil-to-lymphocyte ratio.

We examined the local lymphocytic reaction to tumour. We found that when absent/mild, moderate and severe lymphocytosis at the IM was compared the patient outcomes differed markedly with the moderate and severe groups having a significant survival advantage. It was demonstrated that a moderate-to-severe lymphocytic infiltrate at the IM was associated with a less advanced Dukes' stage, less EMVI and MMR-deficient cancers. The lymphocytic reaction also correlated with NLR in that a moderate-to-severe reaction was significantly less likely to exhibit a raised NLR $(P=0.005)$.

Our study comprises a retrospective cohort of consecutive patients treated in Leeds between 2000 and 2004. There are limitations to the study. The small size of the cohort makes it difficult to draw comprehensive conclusions. The heterogeneous nature of the data (variation in patient physiology, treatment and
Table 2. MMR protein deficiency/proficiency in the NLR groups

\begin{tabular}{|c|c|c|c|c|}
\hline & \multicolumn{4}{|c|}{ NLR } \\
\hline & Total & $<5$ & $\geqslant 5$ & $P$-value ${ }^{a}$ \\
\hline \multicolumn{5}{|l|}{ hMLH-1 } \\
\hline Negative & 45 (12.6\%) & 37 (13.7\%) & 8 (9.1\%) & 0.247 \\
\hline Positive & 291 (81.3\%) & $216(80.0 \%)$ & 75 (85.2\%) & - \\
\hline Unknown & $22(6.1 \%)$ & $17(6.3 \%)$ & $5(5.7 \%)$ & - \\
\hline \multicolumn{5}{|l|}{ hMSH-2 } \\
\hline Negative & 12 (3.4\%) & $8(3.0 \%)$ & $4(4.5 \%)$ & 0.489 \\
\hline Positive & $326(91.1 \%)$ & $246(91.1 \%)$ & 80 (90.9\%) & - \\
\hline Unknown & 20 (5.6\%) & $16(5.9 \%)$ & $4(4.5 \%)$ & - \\
\hline \multicolumn{5}{|c|}{ Final MMR status } \\
\hline Deficient & 55 (15.4\%) & 44 (16.3\%) & 11 (12.5\%) & 0.356 \\
\hline Proficient & 286 (79.9\%) & 212 (78.5\%) & 74 (84.1\%) & - \\
\hline Unknown & $17(4.7 \%)$ & $14(5.2 \%)$ & $3(3.4 \%)$ & \\
\hline \multicolumn{5}{|c|}{$\begin{array}{l}\text { Abbreviations: } \mathrm{NLR}=\text { neutrophil-to-lymphocyte ratio; } \mathrm{MMR}=\text { mismatch repair. } \\
\mathrm{a}^{2}{ }^{2} \text {-test. }\end{array}$} \\
\hline
\end{tabular}

tumour biology) makes comparisons between groups difficult and increases the risk of individual factors skewing the data. We were unable to separate elective and emergency resections. We attempt to correct for this by identifying and excluding patients with evidence of sepsis or bowel perforation. However, emergency presentations have worse outcomes, particularly in the early post-operative period (Ueberrueck et al, 2013). This may bias our results and may contribute to the early mortality seen in the NLR high group.

The relationship between NLR and cancer has been explored elsewhere in the literature. Cho et al (2009) demonstrated that not only was NLR more likely to be elevated in patients with epithelial ovarian cancer, compared with patients with benign conditions and normal controls, but that the pre-treatment value predicted patient survival (Cho et al, 2009). Similar findings have been seen in non-small cell lung cancer (Sarraf et al, 2009). In CRC Walsh et al (2005) examined a cohort of 230 CRC patients over a 2-year period. They found that pre-operative NLR $>5$ correlated with overall and cancer-specific survival on univariate analysis. However, on multivariate analysis it was not independent of Dukes' stage (Walsh et al, 2005). NLR also predicts outcome in stage II (Ding et al, 2010; Hung et al, 2011) and stages I-III CRC (Chiang et al, 2012; Mallappa et al, 2013; Malietzis et al, 2014). It is prognostic in metastatic CRC patients and those with metastatic disease undergoing palliative chemotherapy (Chua et al, 2011; Kaneko et al, 2012). This suggests that NLR is an indicator of prognosis in CRC and, when used with more established predictors, can identify patients who may benefit from adjuvant treatment or more frequent surveillance.

There are a number of mechanisms by which the prognostic effect of NLR may be produced. It is thought to be a simple measure of the systemic inflammatory response and an elevated value may represent tumour-generated inflammation (O'Mahony et al, 1984). If pro-inflammatory cytokines, such as TNF- $\alpha$ and IL's 1,6 and 8, are upregulated as part of an inflammatory response this can have important effects on tumour growth and progression. These inflammatory mediators activate intracellular pathways, such as those mediated by NF- $\kappa \mathrm{B}$, modulate cellular proliferation and angiogenesis and may have a profound effect on tumour growth and invasion.

Lymphocytopenia is an important component of a high NLR and its value may be indicative of the type and degree of lymphocytic response to tumour. A low level of blood-borne lymphocytes may reflect a muted or absent lymphocytic response to tumour. Tumours with an increased population of intraepithelial T-lymphocytes, particularly the CD8 + cytotoxic phenotype, have better outcomes (Dolcetti et al, 1999). The NLR may reflect the type of T-cell response. Evidence suggests 




Numbers at risk
\begin{tabular}{|l|c|c|c|c|c|}
\hline Years & $\mathbf{0}$ & $\mathbf{1}$ & $\mathbf{2}$ & $\mathbf{3}$ & $\mathbf{4}$ \\
\hline None/mild & 240 & 183 & 163 & 134 & 119 \\
\hline Moderate & 103 & 88 & 79 & 74 & 71 \\
\hline Severe & 8 & 7 & 7 & 6 & 6 \\
\hline
\end{tabular}

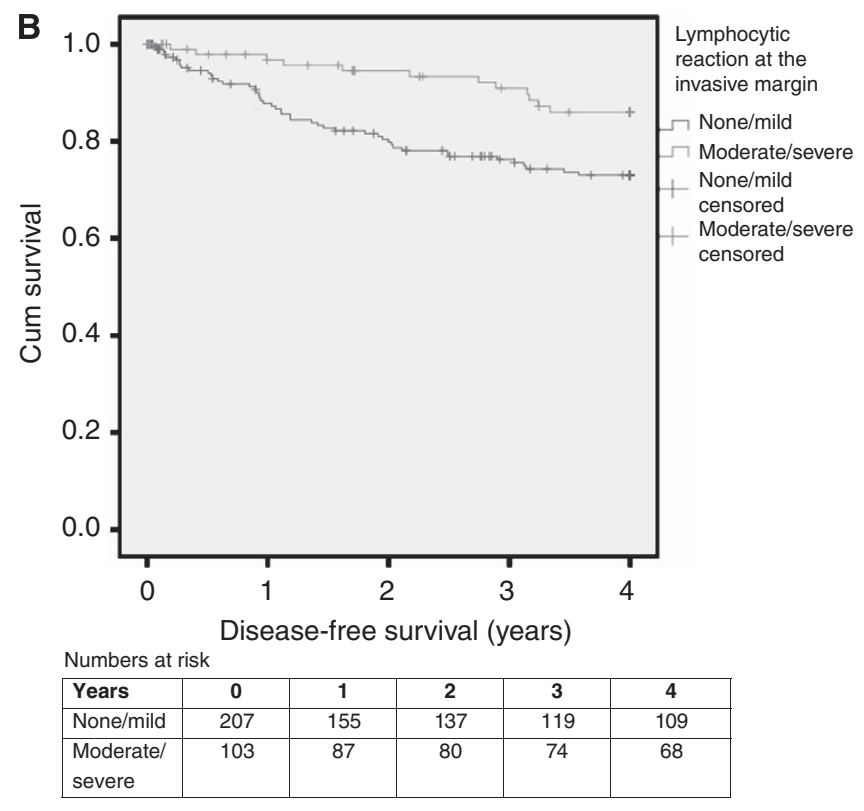

Figure 2. Kaplan-Meier curves showing survival by grade of lymphocytic reaction at the invasive margin. (A) Overall survival ( $n=344, P=0.004, \mathrm{HR} 1.751,95 \% \mathrm{Cl} 1.241-2.469)$. (B) Disease-free survival $(n=310, P=0.010, \operatorname{HR} 1.873,95 \% \mathrm{Cl} 1.065-3.295)$.

that even when lymphocytic aggregates are present in a tumour their immune responsiveness is often blunted by cytokines within the microenvironment (Zippelius et al, 2004). Cells are often polarised away from the anti-tumour Th-1 phenotype towards a more immunosuppressive Th-2 type. This blunts the anti-tumour response and creates a milieu in which tumour cell populations can develop unimpeded (Balkwill and Mantovani, 2001). Cytokines associated with Th-1 polarisation, such as IFN- $\gamma$ or IL-12, and associated pro-inflammatory cytokines, such as IL-2, may also have a role.

As well as being implicated in the inflammatory response and its associated cancer promoting pathways, NLR may also offer an indication of the physiological condition of the patient. In more advanced CRC causing large bowel obstruction, a neutrophilia would be generated. Such patients may have a greater mortality



Numbers at risk
\begin{tabular}{|l|c|c|c|c|c|}
\hline Years & $\mathbf{0}$ & $\mathbf{1}$ & $\mathbf{2}$ & $\mathbf{3}$ & $\mathbf{4}$ \\
\hline None/mild & 313 & 248 & 223 & 190 & 172 \\
\hline Moderate & 39 & 31 & 27 & 25 & 25 \\
\hline
\end{tabular}

Figure 3. Kaplan-Meier curves showing overall survival by grade of lymphocytic reaction at the tumour centre $(n=344, P=0.380)$.

Table 3. Data by grade of lymphocytic reaction at the invasive margin

\begin{tabular}{|c|c|c|c|c|}
\hline & Total & $\begin{array}{l}\text { None/low } \\
\text { density } \\
\text { (Group 1) }\end{array}$ & $\begin{array}{l}\text { Moderate/ } \\
\text { severe density } \\
\text { (Groups } 2 \text { and } 3 \text { ) }\end{array}$ & $P$-value \\
\hline$N$ & 351 & 240 (68.4\%) & $111(31.6 \%)$ & - \\
\hline $\begin{array}{l}\text { Median } \\
\text { age (years) }\end{array}$ & 73 & 73 & 73 & $0.946^{a}$ \\
\hline \multicolumn{5}{|l|}{ Gender } \\
\hline Male & 200 (57.0\%) & $142(59.2 \%)$ & $58(52.3 \%)$ & $0.224^{b}$ \\
\hline Female & 151 (43.0\%) & 98 (40.8\%) & 53 (47.7\%) & - \\
\hline \multicolumn{5}{|c|}{ Site of tumour } \\
\hline Colon & 256 (72.9\%) & 168 (70.0\%) & $88(79.3 \%)$ & $0.069^{b}$ \\
\hline Rectum & 95 (27.1\%) & 72 (30.0\%) & 23 (20.7\%) & - \\
\hline \multicolumn{5}{|c|}{ Dukes' stage } \\
\hline A & 37 (10.5\%) & $17(7.1 \%)$ & 20 (18.0\%) & $0.001^{b}$ \\
\hline B & 157 (44.7\%) & 100 (41.7\%) & 57 (51.4\%) & - \\
\hline C & 119 (33.9\%) & 91 (37.9\%) & 28 (25.2\%) & - \\
\hline D & 37 (10.5\%) & 32 (13.3\%) & $5(4.5 \%)$ & - \\
\hline \multicolumn{5}{|l|}{ EMVI } \\
\hline Yes & 137 (39.0\%) & 105 (43.8\%) & 32 (28.8\%) & $0.01^{b}$ \\
\hline No & 208 (61.0\%) & $132(56.2 \%)$ & 76 (71.2\%) & - \\
\hline \multicolumn{5}{|c|}{ MMR status } \\
\hline Deficient & 55 (15.7\%) & $31(12.9 \%)$ & 24 (21.6\%) & $0.04^{b}$ \\
\hline Proficient & 281 (84.3\%) & 198 (87.1\%) & 83 (78.6\%) & - \\
\hline \multicolumn{5}{|l|}{ NLR } \\
\hline$<5$ & $264(\%)$ & 170 (70.8\%) & 94 (84.7\%) & $0.005^{b}$ \\
\hline$\geqslant 5$ & $87(\%)$ & 70 (29.2\%) & 17 (15.3\%) & \\
\hline \multicolumn{5}{|c|}{$\begin{array}{l}\text { Abbreviations: } E M V I=\text { extramural vascular invasion; } M M R=\text { mismatch repair; } N L R= \\
\text { neutrophil-to-lymphocyte ratio. } \\
\text { a Mann-Whitney U-test. } \text { b }{ }^{2} \text {-test. }\end{array}$} \\
\hline
\end{tabular}

rate than patients without such problems. This may contribute to the impact of NLR on overall survival; however, an elevated NLR is also seen in patients with early stage cancer.

Like others we have demonstrated that the pre-operative systemic NLR predicts both overall survival and disease recurrence following surgery for CRC. However, we have gone onto 
Table 4. Multivariate analysis for overall survival including lymphocytic reaction at invasive margin

\begin{tabular}{|c|c|c|c|c|}
\hline Covariate & $N$ & $P$-value & HR & $95 \% \mathrm{Cl}$ \\
\hline \multicolumn{5}{|l|}{ NLR } \\
\hline$<5$ & 260 & - & 1.00 & - \\
\hline$\geqslant 5$ & 84 & 0.002 & 1.712 & $1.227-2.389$ \\
\hline \multicolumn{5}{|c|}{ Age (years) } \\
\hline$\leqslant 70$ & 123 & - & 1.00 & - \\
\hline$>70$ & 221 & $<0.001$ & 3.008 & $2.067-4.376$ \\
\hline \multicolumn{5}{|l|}{ EMVI } \\
\hline Yes & 138 & - & 1.00 & - \\
\hline No & 212 & 0.144 & 1.294 & $0.916-1.827$ \\
\hline \multicolumn{5}{|c|}{ Dukes' stage } \\
\hline A & 36 & - & 1.00 & - \\
\hline B & 152 & 0.635 & 0.857 & $0.454-1.619$ \\
\hline C & 119 & 0.089 & 1.763 & $0.916-3.392$ \\
\hline D & 37 & $<0.001$ & 5.649 & $2.731-11.683$ \\
\hline \multicolumn{5}{|c|}{ Lymphocytic reaction (grade) } \\
\hline None/mild & 237 & - & 1.00 & - \\
\hline $\begin{array}{l}\text { Moderate/ } \\
\text { severe }\end{array}$ & 107 & 0.135 & 0.757 & $0.526-1.090$ \\
\hline
\end{tabular}

Table 5. Multivariate analysis for disease-free survival including lymphocytic reaction at invasive margin

\begin{tabular}{|c|c|c|c|c|}
\hline Covariate & $N$ & $P$-value & HR & $95 \% \mathrm{Cl}$ \\
\hline \multicolumn{5}{|l|}{ NLR } \\
\hline$<5$ & 234 & - & 1.00 & - \\
\hline$\geqslant 5$ & 65 & 0.007 & 2.185 & $1.233-3.871$ \\
\hline \multicolumn{5}{|c|}{ Complete resection } \\
\hline Yes & 106 & - & 1.00 & - \\
\hline No & 193 & 0.355 & 0.727 & $0.370-1.429$ \\
\hline \multicolumn{5}{|l|}{ EMVI } \\
\hline Yes & 270 & - & 1.00 & - \\
\hline No & 29 & 0.007 & 2.187 & $1.234-3.874$ \\
\hline \multicolumn{5}{|c|}{ Dukes' stage } \\
\hline A & 36 & - & 1.00 & - \\
\hline B & 150 & 0.797 & 0.864 & $0.284-2.631$ \\
\hline C & 113 & 0.084 & 2.660 & $0.877-8.064$ \\
\hline \multicolumn{5}{|c|}{ Lymphocytic reaction (grade) } \\
\hline None/mild & 201 & - & 1.00 & - \\
\hline $\begin{array}{l}\text { Moderate/ } \\
\text { severe }\end{array}$ & 98 & 0.253 & 1.420 & $0.778-2.589$ \\
\hline
\end{tabular}

demonstrate a strong association of NLR with histopathology features of the local immune response rather than MMR status and the frequency of nodal involvement and EMVI. While the immunological mechanism for this phenomenon remains unclear, this represents a cheap, easily accessible test that can provide valuable prognostic information prior to surgical intervention. Further work is needed to investigate the immunological basis for these observations, as well as whether they affect the developing immunotherapeutic approaches in such patients.

\section{ACKNOWLEDGEMENTS}

PQ is supported by a programme grant from Yorkshire Cancer Research (YCR), and NPW was supported by a research fellowship also from YCR. EM was supported by a Career Development Fellowship from CRUK's Bobby Moore Fund (C23434/A9805), and DGJ is an NIHR Professor of Surgery and JKP was supported by the Leeds Teaching Hospitals NHS Trust.

\section{CONFLICT OF INTEREST}

The authors declare no conflict of interest.

\section{REFERENCES}

Absenger G, Szkandera J, Stotz M, Postlmayr U, Pichler M, Ress AL, SchaberlMOSER R, Loibner H, Samonigg H, Gerger A (2013) Preoperative neutrophil-to-lymphocyte ratio predicts clinical outcome in patients with stage II and III colon cancer. Anticancer Res 33: 4591-4594.

Balkwill F, Mantovani A (2001) Inflammation and cancer: back to Virchow? Lancet 357: 539-545.

Chiang SF, Hung HY, Tang R, Changchien CR, Chen JS, You YT, Chiang JM, Lin JR (2012) Can neutrophil-to-lymphocyte ratio predict the survival of colorectal cancer patients who have received curative surgery electively? Int J Colorectal Dis 27: 1347-1357.

Cho H, Hur HW, Kim SW, Kim SH, Kim JH, Kim YT, Lee K (2009) Pre-treatment neutrophil to lymphocyte ratio is elevated in epithelial ovarian cancer and predicts survival after treatment. Cancer Immunol Immunother 58: 15-23.

Chua W, Charles KA, Baracos VE, Clarke SJ (2011) Neutrophil/lymphocyte ratio predicts chemotherapy outcomes in patients with advanced colorectal cancer. Br J Cancer 104: 1288-1295.

Courtney ED, West NJ, Kaur C, Ho J, Kalber B, Hagger R, Finlayson C, Leicester RJ (2009) Extramural vascular invasion is an adverse prognostic indicator of survival in patients with colorectal cancer. Colorectal Dis 11: $150-156$.

Coussens LM, Werb Z (2002) Inflammation and cancer. Nature 420: 860-867. Cancer Research UK (2011) Bowel Cancer Statistics. http:// www.cancerresearchuk.org/cancer-info/cancerstats/types/bowel/.

de Visser KE, Eichten A, Coussens LM (2006) Paradoxical roles of the immune system during cancer development. Nat Rev Cancer 6: 24-37.

Deans GT, Patterson CC, Parks TG, Spence RA, Heatley M, Moorehead RJ, Rowlands BJ (1994) Colorectal carcinoma: importance of clinical and pathological factors in survival. Ann R Coll Surg Engl 76: 59-64.

Ding PR, An X, Zhang RX, Fang YJ, Li LR, Chen G, Wu XJ, Lu ZH, Lin JZ, Kong LH, Wan DS, Pan ZZ (2010) Elevated preoperative neutrophil to lymphocyte ratio predicts risk of recurrence following curative resection for stage IIA colon cancer. Int J Colorectal Dis 25: 1427-1433.

Dolcetti R, Viel A, Doglioni C, Russo A, Guidoboni M, Capozzi E, Vecchiato N, Macri E, Fornasarig M, Boiocchi M (1999) High prevalence of activated intraepithelial cytotoxic $\mathrm{T}$ lymphocytes and increased neoplastic cell apoptosis in colorectal carcinomas with microsatellite instability. Am J Pathol 154: 1805-1813.

Drescher KM, Sharma P, Watson P, Gatalica Z, Thibodeau SN, Lynch HT (2009) Lymphocyte recruitment into the tumor site is altered in patients with MSI-H colon cancer. Fam Cancer 8: 231-239.

Galon J, Costes A, Sanchez-Cabo F, Kirilovsky A, Mlecnik B, Lagorce-Pages C, Tosolini M, Camus M, Berger A, Wind P, Zinzindohoue F, Bruneval P, Cugnenc PH, Trajanoski Z, Fridman WH, Pages F (2006) Type, density, and location of immune cells within human colorectal tumors predict clinical outcome. Science 313: 1960-1964.

Gerhardt T, Milz S, Schepke M, Feldmann G, Wolff M, Sauerbruch T, Dumoulin FL (2006) C-reactive protein is a prognostic indicator in patients with perihilar cholangiocarcinoma. World J Gastroenterol 12: 5495-5500.

Gill S, Loprinzi CL, Sargent DJ, Thome SD, Alberts SR, Haller DG, Benedetti J, Francini G, Shepherd LE, Francois SEITZ J, Labianca R, Chen W, Cha SS, Heldebrant MP, Goldberg RM (2004) Pooled analysis of fluorouracilbased adjuvant therapy for stage II and III colon cancer: who benefits and by how much? J Clin Oncol 22: 1797-1806.

Gryfe R, Kim H, Hsieh ET, Aronson MD, Holowaty EJ, Bull SB, Redston M, Gallinger S (2000) Tumor microsatellite instability and clinical outcome in young patients with colorectal cancer. N Engl J Med 342: 69-77. 
Guidoboni M, Gafa R, Viel A, Doglioni C, Russo A, Santini A, del Tin L, Macri E, Lanza G, Boiocchi M, Dolcetti R (2001) Microsatellite instability and high content of activated cytotoxic lymphocytes identify colon cancer patients with a favorable prognosis. Am J Pathol 159: 297-304.

Halazun KJ, Aldoori A, Malik HZ, Al-Mukhtar A, Prasad KR, Toogood GJ, Lodge JP (2008) Elevated preoperative neutrophil to lymphocyte ratio predicts survival following hepatic resection for colorectal liver metastases. Eur J Surg Oncol 34: 55-60.

Hanahan D, Weinberg RA (2011) Hallmarks of cancer: the next generation. Cell 144: 646-674.

Hilmy M, Bartlett JM, Underwood MA, Mcmillan DC (2005) The relationship between the systemic inflammatory response and survival in patients with transitional cell carcinoma of the urinary bladder. Br J Cancer 92: 625-627.

Hung HY, Chen JS, Yeh CY, Changchien CR, Tang R, Hsieh PS, Tasi WS, You JF, You YT, Fan CW, Wang JY, Chiang JM (2011) Effect of preoperative neutrophil-lymphocyte ratio on the surgical outcomes of stage II colon cancer patients who do not receive adjuvant chemotherapy. Int J Colorectal Dis 26: 1059-1065.

Hutchins G, Southward K, Handley K, Magill L, Beaumont C, Stahlschmidt J, Richman S, Chambers P, Seymour M, Kerr D, Gray R, Quirke P (2011) Value of mismatch repair, KRAS, and BRAF mutations in predicting recurrence and benefits from chemotherapy in colorectal cancer. J Clin Oncol 29: 1261-1270.

Jamieson NB, Glen P, Mcmillan DC, Mckay CJ, Foulis AK, Carter R, Imrie CW (2005) Systemic inflammatory response predicts outcome in patients undergoing resection for ductal adenocarcinoma head of pancreas. Br J Cancer 92: 21-23.

Kaneko M, Nozawa H, Sasaki K, Hongo K, Hiyoshi M, Tada N, Murono K, Nirei T, Kawai K, Sunami E, Tsuno NH, Kitayama J (2012) Elevated neutrophil to lymphocyte ratio predicts poor prognosis in advanced colorectal cancer patients receiving oxaliplatin-based chemotherapy. Oncology 82: 261-268.

Klintrup K, Makinen JM, Kauppila S, Vare PO, Melkko J, Tuominen H, Tuppurainen K, Makela J, Karttunen TJ, Makinen MJ (2005) Inflammation and prognosis in colorectal cancer. Eur J Cancer 41: 2645-2654.

Lamb GW, Mcardle PA, Ramsey S, Mcnichol AM, Edwards J, Aitchison M, Mcmillan DC (2008) The relationship between the local and systemic inflammatory responses and survival in patients undergoing resection for localized renal cancer. BJU Int 102: 756-761.

Lanza G, Gafa R, Santini A, Maestri I, Guerzoni L, Cavazzini L (2006) Immunohistochemical test for MLH1 and MSH2 expression predicts clinical outcome in stage II and III colorectal cancer patients. J Clin Oncol 24: $2359-2367$.

Lievre A, Bachet JB, Le Corre D, Boige V, Landi B, Emile JF, Cote JF, Tomasic G, Penna C, Ducreux M, Rougier P, Penault-Llorca F, Laurent-Puig P (2006) KRAS mutation status is predictive of response to cetuximab therapy in colorectal cancer. Cancer Res 66: 3992-3995.

Malietzis G, Giacometti M, Askari A, Nachiappan S, Kennedy RH, Faiz OD, Aziz O, Jenkins JT (2014) A preoperative neutrophil to lymphocyte ratio of 3 predicts disease-free survival after curative elective colorectal cancer surgery. Ann Surg 260: 287-292.

Mallappa S, Sinha A, Gupta S, Chadwick SJ (2013) Preoperative neutrophil to lymphocyte ratio $>5$ is a prognostic factor for recurrent colorectal cancer. Colorectal Dis 15: 323-328.

Martling AL, Holm T, Rutqvist LE, Moran BJ, Heald RJ, Cedemark B (2000) Effect of a surgical training programme on outcome of rectal cancer in the County of Stockholm. Stockholm Colorectal Cancer
Study Group, Basingstoke Bowel Cancer Research Project. Lancet 356: $93-96$.

Mckeown DJ, Brown DJ, Kelly A, Wallace AM, Mcmillan DC (2004) The relationship between circulating concentrations of C-reactive protein, inflammatory cytokines and cytokine receptors in patients with non-small-cell lung cancer. Br J Cancer 91: 1993-1995.

Mcmillan DC, Canna K, Mcardle CS (2003) Systemic inflammatory response predicts survival following curative resection of colorectal cancer. Br J Surg 90: $215-219$.

Nozoe T, Saeki H, Sugimachi K (2001) Significance of preoperative elevation of serum C-reactive protein as an indicator of prognosis in esophageal carcinoma. Am J Surg 182: 197-201.

O’Mahony JB, Palder SB, Wood JJ, Mcirvine A, Rodrick ML, Demling RH, Mannick JA (1984) Depression of cellular immunity after multiple trauma in the absence of sepsis. J Trauma 24: 869-875.

Pages F, Berger A, Camus M, Sanchez-Cabo F, Costes A, Molidor R, Mlecnik B, Kirilovsky A, Nilsson M, Damotte D, Meatchi T, Bruneval P, Cugnenc PH, Trajanoski Z, Fridman WH, Galon J (2005) Effector memory T cells, early metastasis, and survival in colorectal cancer. $N$ Engl J Med 353: 2654-2666.

Popat S, Hubner R, Houlston RS (2005) Systematic review of microsatellite instability and colorectal cancer prognosis. J Clin Oncol 23: 609-618.

Sarraf KM, Belcher E, Raevsky E, Nicholson AG, Goldstraw P, Lim E (2009) Neutrophil/lymphocyte ratio and its association with survival after complete resection in non-small cell lung cancer. J Thorac Cardiovasc Surg 137: $425-428$.

Streiner D, Norman G (1995) Health Measurement Scales: a Practical Guide to Their Development and Use. Oxford University Press: New York, NY, USA.

Ueberrueck T, Wurst C, Rauchfuss F, Knosel T, Settmacher U, AltendorfHofmann A (2013) What factors influence 10-year survival after curative resection of a colorectal carcinoma? World J Surg 37: 2476-2482.

Walsh SR, Cook EJ, Goulder F, Justin TA, Keeling NJ (2005) Neutrophillymphocyte ratio as a prognostic factor in colorectal cancer. J Surg Oncol 91: 181-184.

Wong VK, Malik HZ, Hamady ZZ, Al-Mukhtar A, Gomez D, Prasad KR, Toogood GJ, Lodge JP (2007) C-reactive protein as a predictor of prognosis following curative resection for colorectal liver metastases. Br J Cancer 96: 222-225.

Wood DA (1971) Clinical staging and end results classification: TNM system of clinical classification as applicable to carcinoma of the colon and rectum. Cancer 28: 109-114.

Zahorec R (2001) Ratio of neutrophil to lymphocyte counts-rapid and simple parameter of systemic inflammation and stress in critically ill. Bratisl Lek Listy 102: 5-14.

Zippelius A, Batard P, Rubio-Godoy V, Bioley G, Lienard D, Lejeune F, Rimoldi D, Guillaume P, Meidenbauer N, Mackensen A, Rufer N, Lubenow N, Speiser D, Cerottini JC, Romero P, Pittet MJ (2004) Effector function of human tumor-specific CD8 T cells in melanoma lesions: a state of local functional tolerance. Cancer Res 64: 2865-2873.

This work is published under the standard license to publish agreement. After 12 months the work will become freely available and the license terms will switch to a Creative Commons AttributionNonCommercial-Share Alike 4.0 Unported License

Supplementary Information accompanies this paper on British Journal of Cancer website (http://www.nature.com/bjc) 